\title{
Isolation and Characterization of Multidrug Resistant Escherichia coli and Salmonella spp from the Wastes of Hospital Patients and Poultry
}

\author{
Abanti Barua ${ }^{1}$, Abu Sayeed Mohammad Mahmud ${ }^{2 *}$, Muhammad Shahjalal \\ Khan $^{3}$, Tarannum Taznin ${ }^{4}$, Muhammad Ehteshamul Haque ${ }^{5}$, Faridul Islam ${ }^{6}$, \\ Naznin Akhtar ${ }^{7}$, Md. Abdul Hakim ${ }^{8}$ \\ ${ }^{I}$ Department of Microbiology, University of Chittagong, Bangladesh \\ ${ }^{2}$ Industrial Microbiology Research Division, BCSIR Lab, Chittagong, Chittagong 4220, Bangladesh. \\ ${ }^{3}$ Department of Microbiology, NOVO Healthcare and Pharma Ltd., Dhaka, Bangladesh \\ ${ }^{4}$ Department of Microbiology, Jessore Science and Technology University (JSTU), Jessore, Bangladesh. \\ ${ }^{5}$ Department of Microbiology, Medinova Medical Services Ltd., Dhanmondi, Dhaka, Bangladesh \\ ${ }^{6}$ Drug and Toxin Research Division, BCSIR Lab, Chittagong, Chittagong 4220, Bangladesh \\ ${ }^{7}$ Tissue Banking and Biomaterial Unit, Atomic Energy Commission Establishment, Dhaka, Bangladesh \\ ${ }^{8}$ Department of Microbiology, University of Chittagong, Bangladesh \\ This work was carried out in collaboration between all authors. We all are the team member of this research \\ work. All are having equal contribution for this research work. All authors read and approved the final \\ manuscript.
}

\begin{abstract}
Total 20 Isolates Of E. Coli (12 From Poultry And 8 From Hospital) Were Isolated Randomly From Poultry Farm Waste And Chittagong Medical College Hospital (Cmch) Liquid Waste. We Found Tetracycline Resistant E. Coli $(150 \mu \mathrm{g} / \mathrm{Ml})$ From The Poultry Farm Waste Sample And Ciprofloxacin Resistant Strain $(3000 \mu \mathrm{g} / \mathrm{Ml})$ From Hospital Waste. Our Finding Suggests That Antibiotic Should Not Be Used In The Growth Promotion Of The Poultry Farm And The Use Of Antibiotics By The Respective Users Need To Be Monitored Properly In Order To Avoid The Emergence Of Antibiotic Resistance In Bacteria.

Abbreviations $C M C H=$ Chittagong Medical College Hospital; $B P=$ British Pharmacopoeia; $P C A=$ plate count agar; $E M B=$ Eosine Methylene Blue; BSA=Bismuth Sulfate Agar; NA= Nutrient Agar; TSI= Triple Sugar Iodine; $B G A=$ Brilliant Green Agar.
\end{abstract}

Keywords: Multidrug resistant; hospital wastes; poultry wastes; Escherichia coli; Salmonella; ciprofloxacin and tetracycline.

\section{Introduction}

Microbes are widely spread out in nature. The presence of resistant bacteria in food and food producing animals has led to much more question and assumption about the transmission of these bacteria from animals to humans. The microbiological food safety is an increasing public health concern worldwide. Many epidemiological studies and research have implicated foods of animal origin as major vehicles associated with illnesses caused by Escherichia coli, Campylobacter, Salmonella and Yersinia spp. [1]. Antibiotics have been used successfully in poultry for different purposes such as growth promotion, prophylaxis, or therapeutics. However, their use in animal production and human therapy has resulted in increased bacterial resistance to many [2]. As a result, chicken and meat can harbor antimicrobial-resistant strains that can be transmitted to humans.

During the past two decades, severe outbreaks of gastrointestinal illness have occurred by food borne pathogenic Escherichia coli, especially 0157:H7 [3]. Escherichia coli are one of the common microbial floras of gastrointestinal tract of poultry and human being [4]. Although most isolates of Escherichia coli are nonpathogenic but they are considered as indicator of faecal contamination in food and about 10 to $15 \%$ of intestinal coliforms are opportunistic and pathogenic serotypes [5] and cause a variety of lesions in immunocompromised hosts as well as in poultry. Among the diseases some are often severe and sometimes lethal infections such as meningitis, endocarditis, urinary tract infection, septicemia, epidemic diarrhea of adults and children [6] and yolk sac infection, omphalitis, cellulitis, swollen head syndrome, coligranuloma, and colibacillosis [7]. Salmonella may cause three types of infection namely enteric fever (typhoid and paratyphoid fever), enterocolitis (gastroenteritis) and septicemia in human [8]. Typhoid fever is one of the major causes of morbidity and mortality in developing countries [9]. In the last two decades, the worldwide emergence of multiresistant Salmonellae has led to the application of fluoroquinolones and broad-spectrum cephalosporins against 
Salmonella infections [10]. However, nalidixic acid-resistant strains (MIC, $>32 \mathrm{mg} /$ liter) exhibiting reduced susceptibility to ciprofloxacin (MICs, 0.125 to $1 \mathrm{mg} /$ liter) have emerged and become endemic in South and South-East Asia [11]. Such strains have also been reported from other parts of the world [12, 13]. Consequently, there is treatment failure with ciprofloxacin in patients infected with these organisms [14]. Enteric fever isolates that are either multidrug resistant or with reduced susceptibility to ciprofloxacin reported from expatriate workers of South Asian origin from Kuwait $[14,15]$. There is no specific link between hospital and poultry but in both place antibiotic uses are more frequent. Here we tried to find out the level of contamination and resistant profile in both places.

\subsection{Sample Collection}

II. Materials And Methods

Samples were collected from Chittagong Medical College $(\mathrm{CMCH})$ hospital and Jayson poultry farm, north featherbed, Chittagong. In various ward of the hospital, the hospitalized patients released their discharges (stool, urine, etc.) in the toilet. Sample 1 Liquid hospital waste collected from the safety tank of the CMCH. Sample 2 Hospital waste discharged collected from the sewage system drain to which the wastes of hospital were outlet from the safety tank. Sample 3 Municipal sewerage system waste collected from municipal sewerage drain collecting the waste from hospital waste. Poultry samples were collected from the wastes position and named as following. Sample 1: Fresh chicken feces collected from the Jayson poultry farm that is placed in north featherbed, Chittagong. Sample 2 Liquid wastes collected from the drain through where the waste materials are discharged out of the farm area. Sample 3 the field where these waste materials are finally thrown away.

\subsection{Isolation and Characterization of Resistant Escherichia Coli and Salmonella Spp from Samples}

Isolation of tetracycline resistant Escherichia coli and Salmonella spp from poultry waste: Tetracycline resistant Escherichia coli were isolated from the sample 1,2 and 3 collected from poultry waste and tetracycline resistant Salmonella were isolated from the sample 1,2 and 3 collected from poultry waste.

\subsubsection{Transferring single colonies of Escherichia coli from NA plates to EMB agar media}

Single colonies were picked up by sterile tooth picks randomly from the PCA plates (with tetracycline in case of samples collected from the poultry farm). The colonies were then patched on an Eosine Methylene Blue (EMB) agar plate containing $30 \mu \mathrm{g} / \mathrm{ml}$ tetracycline in case of poultry waste samples to isolate the E.coli colonies. The EMB plates were then allowed for incubation at $37^{\circ} \mathrm{C}$ for 24 hours.

\subsubsection{Transferring single colonies of Salmonella spp from NA plates to Brilliant Green Agar (BGA) plate and Bismuth Sulphate Agar (BSA)}

Single colonies were picked up by sterile tooth picks randomly from the PCA plates (with tetracycline in case of samples collected from the poultry farm). The colonies were then patched on Brilliant Green Agar (BGA) plate and Bismuth Sulphate Agar (BSA) plate for isolating the Salmonella colony plate containing 30 $\mu \mathrm{g} / \mathrm{ml}$ tetracycline in case of poultry waste samples. The plates were then allowed for incubation at $37^{\circ} \mathrm{C}$ for 24 hours.

\subsubsection{Isolation of ciprofloxacin resistant Escherichia coli and Salmonella spp from hospital wastes}

Ciprofloxacin resistant $E$. coli were isolated from the sample 1 and 2 collected from hospital waste of $\mathrm{CMCH}$ and ciprofloxacin resistant Salmonella were isolated from the sample 1 collected from hospital waste of $\mathrm{CMCH}$.

\subsubsection{Transferring single colonies of Escherichia coli from NA plates to EMB agar media}

Single colonies were picked up by sterile tooth picks randomly from the PCA plates (with Ciprofloxacin in case of samples collected from the hospital). The colonies were then patched on an Eosine Methylene Blue (EMB) agar plate containing $30 \mu \mathrm{g} / \mathrm{ml}$ ciprofloxacin in case of hospital waste samples to isolate the E.coli colonies. The EMB plates were then allowed for incubation at $37^{\circ} \mathrm{C}$ for 24 hours.

\subsubsection{Transferring single colonies of Salmonella spp from NA plates to Brilliant Green Agar (BGA) plate and Bismuth Sulphate Agar (BSA)}

Single colonies were picked up by sterile tooth picks randomly from the PCA plates (with ciprofloxacin in case of samples collected from the hospital sample). The colonies were then patched on Brilliant Green Agar (BGA) plate and Bismuth Sulphate Agar (BSA) plate for isolating the Salmonella colony plate containing 30 
$\mu \mathrm{g} / \mathrm{ml}$ Ciprofloxacin in case of hospital waste samples. The plates were then allowed for incubation at $37^{\circ} \mathrm{C}$ for 24 hours.

\subsubsection{Microscopic examination of morphology bacteria}

The size, shape, arrangements and Gram reactions of the 24 hour bacterial cultures were observed in a microscopical field [16].
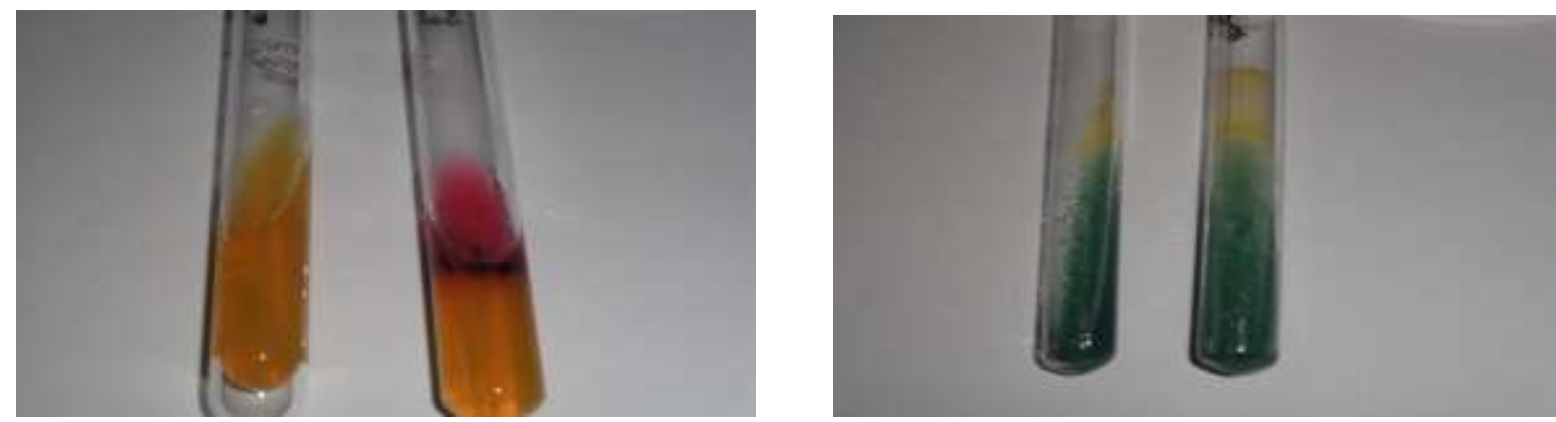

\subsubsection{Conventional biochemical test for the identification of E.coli and Salmonella}

Conventional Biochemical tests employed for the identification of E.coli and Salmonella were Motility test [17], Indole test [18], Citrate test [19], Lactose fermentation test [20], Voges-proskauer (V.P.) test [18], Methyl-red test [18] Test on TSI Agar [18], Urease production test [17] It should be mentioned first in all cases of identification antibiotics (tetracycline $30 \mu \mathrm{g} / \mathrm{ml}$ for the poultry isolates and ciprofloxacin $30 \mu \mathrm{g} / \mathrm{ml}$ for the hospital isolates) were maintained.

\subsection{Materials}

Ciprofloxacin HCl BP, Tetracycline BP, Penicillin G BP, Ampicillin BP, Amoxicillin BP were gift sample from Standard laboratories Ltd, Chittagong, Bangladesh. All the reagent and analytical kids were used during different tests were reagent grade.

\subsection{Antibiotic Susceptibility Analysis}

\subsubsection{Disc diffusion method}

The standardized disc diffusion method also known as Kirby Bauer method [21] was used for the in vitro determination of the sensitivity to the antimicrobial agents. The antibiotic sensitivity of the isolated strain at different concentration was performed by using standard paper discs with different concentration. We used $5 \mu \mathrm{g}$, $10 \mu \mathrm{g}$ and $20 \mu \mathrm{g}$ ciprofloxacin paper disc in case of hospital waste isolates to measure the resistance pattern of the isolates against this antibiotic. Similarly, we used $10 \mu \mathrm{g}, 20 \mu \mathrm{g}$ and $30 \mu \mathrm{g}$ tetracycline paper disc in case of poultry waste isolates to measure the resistance pattern of the isolates against this antibiotic.
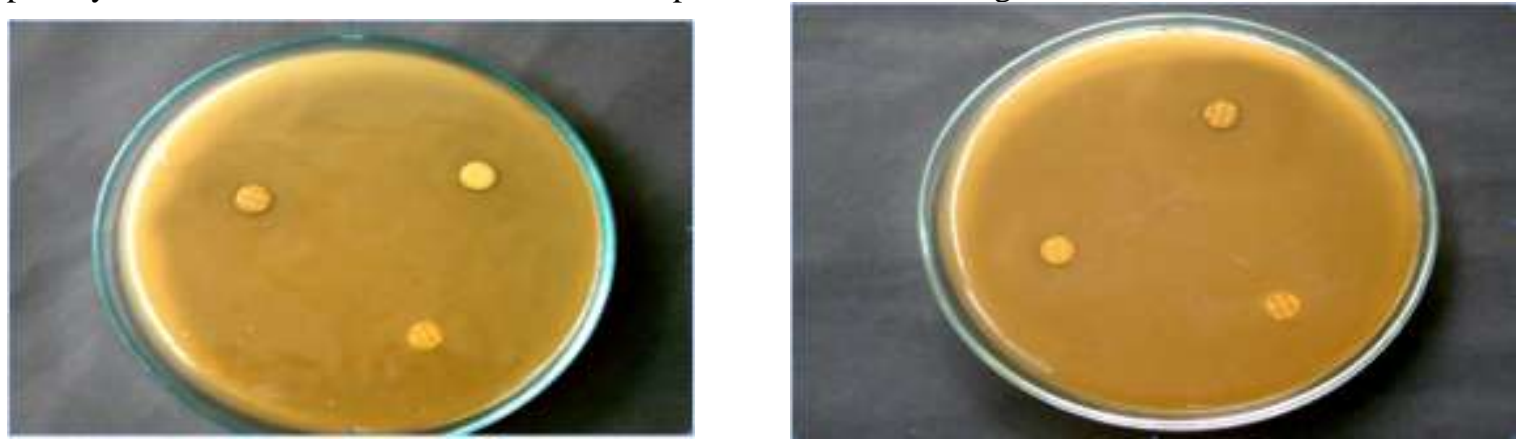

\subsubsection{MDR determination}

Antibiotic sensitivity test of the ciprofloxacin and tetracycline resistant E.coli and Salmonella were done by disc diffusion method [19] on Agar medium with disks containing amoxicillin (10 $\mu \mathrm{g})$, ampicillin (10 $\mu \mathrm{g})$, tetracycline $(30 \mu \mathrm{g})$, Penicillin $\mathrm{G}(10 \mu \mathrm{g})$ and ciprofloxacin $(50 \mu \mathrm{g})$.

\subsubsection{Turbidity method: Culture preparation and absorbance measurement}

Bacteria were grown in the broth and incubated for 24 hours at $37^{\circ} \mathrm{C}$. The 40 hour old broth cultures were taken and each of them are dispensed in small vials containing $1 \mathrm{ml}$ of Muller-Hinton broth containing different concentration of antibiotics $(30 \mu \mathrm{g} / \mathrm{ml}$ of ciprofloxacin in case of hospital waste samples and tetracycline $30 \mu \mathrm{g} / \mathrm{ml}$ for the poultry samples). The rate of inoculums transfer is 1:200. A control for each of the 
culture was maintained by keeping a vial without inoculation. The vials were then incubated at $37^{\circ} \mathrm{C}$ for 24 hours. By using light absorbance technique, the growth of bacteria was measured at $590 \mathrm{~nm}$ in a spectrophotometer. Then the resistant pattern was analyzed by drawing a graph using the chart of absorbance in different concentrations of tetracycline $(40 \mu \mathrm{g} / \mathrm{ml}-150 \mu \mathrm{g} / \mathrm{ml})$ in case of poultry samples and ciprofloxacin (200 $\mu \mathrm{g} / \mathrm{ml}$ to $3000 \mu \mathrm{g} / \mathrm{ml}$ ) in case of samples collected from hospital waste.

\section{Results And Discussions}

3.1 Isolation of Tetracycline and Ciprofloxacin Resistant E. coli and Salmonella

A total of 20 individual colonies of Escherichia coli (12 from poultry sample and 8 from the hospital waste samples) were isolated. From the tetracycline containing nutrient agar plates were patched in the tetracycline containing EMB and MacConkey agar plate for the isolation of tetracycline resistant Escherichia coli from the poultry sample. Similarly, from the Ciprofloxacin containing nutrient agar plates were patched in the Ciprofloxacin containing EMB and MacConkey agar plate for the isolation of Ciprofloxacin resistant E.coli from the $\mathrm{CMCH}$ sample. Characteristic metallic sheen on the EMB agar plates and pink colony in the MacConkey agar plates of the isolates assure the presence of Escherichia coli. In the poultry sample no Ciprofloxacin resistant strain was observed.

The isolated colonies were identified by conventional biochemical test. A total of 15 individual colonies of Salmonella (10 from poultry sample and 5 from the hospital waste samples) were isolated. From the tetracycline containing nutrient agar plates were patched in the tetracycline containing BGA and BSA agar plate for the isolation of tetracycline resistant Salmonella from the poultry sample. Similarly, from the Ciprofloxacin containing nutrient agar plates were patched in the Ciprofloxacin containing BGA and BSA agar plate for the isolation of Ciprofloxacin resistant Salmonella from the CMCH sample.

Characteristic black colonies on the BSA plate and whitish colony on the BGA plate with turning the plate red to yellow was observed after incubation of the isolates. In the poultry sample no Ciprofloxacin resistant strain was observed. The isolated colonies were identified by conventional biochemical test. Total experimental results are summarized in Table 1.

\subsection{Isolation of Tetracycline Resistant Escherichia coli and Salmonella spp}

Tetracycline resistant 12 Escherichia coli and 10 Salmonella isolates from poultry sample in different concentration of tetracycline were isolated from poultry sample. Results are summarized in Table 2.

Table 1. Identification test result of Escherichia coli and Salmonella spp

\begin{tabular}{lll}
\hline Test & Test result & \\
\hline Colony character & E.coli & Salmonella \\
EMB & Metallic Sheen colony & - \\
MacConkey & Pink Colony & - \\
BSA & -- & Black colony \\
BGA & -- & Pink white colony \\
Biochemical test & & \\
Motility & + & + \\
Lactose fermentation Test & + & - \\
Indole test & + & - \\
Methyl red test & + & + \\
Voges-proskauer test & - & - \\
Citrate test & - & - \\
H2S test & - & + \\
Urease & - & - \\
Presumptive test (TSI) & - (Yellow) & Alkaline (Red) \\
Slant & - (Yellow) & Acidic (Yellow) \\
Butt & - & + \\
Gas & \multicolumn{2}{c}{ Positive result, - Negative result. - Not performed. }
\end{tabular}

\subsection{Isolation of Ciprofloxacin Resistant Escherichia coli and Salmonella spp}

Ciprofloxacin resistant 8 Escherichia coli and 5 Salmonella isolates from poultry sample in different concentration of Ciprofloxacin. Results are summarized in Table 3. 


\subsection{Multidrug Resistant Pattern Analysis}

All Escherichia coli and Salmonella isolates from hospital samples were found to be multidrug resistant as they were not sensitive against several commercial antibiotics. Results are summarized in Table 4.

\section{Discussion}

Our studies on the prevalence and antimicrobial resistance profiles of Escherichia coli and Salmonella from poultry and hospital wastes from Chittagong, Bangladesh, revealed a high level of contamination. Ciprofloxacin and tetracycline resistant Escherichia coli and Salmonella spp. Isolated from hospital and poultry samples. The isolates are identified by different biochemical methods. All results are summarized in table 1 . According to the colony character, presumptive test and biochemical test results, the isolates were found to belong to Escherichia coli and Salmonella spp (Table- 1).12 tetracycline resistant Escherichia coli and 10 tetracycline resistant Salmonella spp isolated from poultry samples. 8 ciprofloxacin resistant Escherichia coli and 5 ciprofloxacin resistant Salmonella spp isolated from hospital samples. After consumption, undigested portion of ciprofloxacin and tetracycline were entered into septic tank with patient discharges (urine, stool etc.) So, the microbes available in the septic tank became resistant. From sample 3 (outside drain through which septic tank wastes release into the environment), microbes are spreading around the CMC. As like as CMC, in poultry also resistant microbes are forming and spreading surrounding. Both may create a great health hazard in Chittagong city near future.

Table 2. Analysis of resistant pattern of 12 Escherichia coli and 10 Salmonella isolates from poultry sample in different concentration of tetracycline

\begin{tabular}{llllll}
\hline E.coli Isolates & $\begin{array}{l}\text { Conc. of } \\
\text { tetracycline }\end{array}$ & $\begin{array}{l}\text { Absorbance } \\
\text { at 590 nm }\end{array}$ & $\begin{array}{l}\text { Salmonella } \\
\text { Isolates }\end{array}$ & $\begin{array}{l}\text { Conc. of } \\
\text { tetracycline }\end{array}$ & $\begin{array}{l}\text { Absorbance } \\
\text { at 590 nm }\end{array}$ \\
\hline ERTP1 & 100 & 0.31 & SRTP1 & 100 & 0.2 \\
& 150 & 0.13 & & 150 & 0.13 \\
ERTP2 & 100 & 0.34 & SRTP2 & 100 & 0.2 \\
& 150 & 0.1 & & 150 & 0.04 \\
ERTP3 & 100 & 0.25 & SRTP3 & 100 & 0.28 \\
& 150 & 0.12 & & 150 & 0.11 \\
ERTP4 & 100 & 0.31 & SRTP4 & 100 & 0.1 \\
& 150 & 0.03 & & 150 & 0.01 \\
ERTP5 & 100 & 0.12 & SRTP5 & 100 & 0.42 \\
& 150 & 0.06 & & 150 & 0.39 \\
ERTP6 & 100 & 0.08 & SRTP6 & 100 & 0.35 \\
& 150 & 0.02 & & 150 & 0.12 \\
ERTP7 & 100 & 0.32 & & 80 & 0.48 \\
& 150 & 0.11 & SRTP7 & 100 & 0.32 \\
ERTP8 & 100 & 0.38 & & 150 & 0.19 \\
& 150 & 0.19 & & 80 & 0.4 \\
ERTP9 & 100 & 0.14 & SRTP8 & 100 & 0.31 \\
& 150 & 0.09 & & 150 & 0.12 \\
ERTP10 & 100 & 0.18 & & 80 & 0.76 \\
& 150 & 0.12 & SRTP9 & 100 & 0.64 \\
ERTP11 & 100 & 0.32 & & 150 & 0.5 \\
& 150 & 0.18 & & 80 & 0.43 \\
ERTP12 & 100 & 0.3 & SRTP10 & 100 & 0.28 \\
& 150 & 0.19 & & 150 & 0.21 \\
\hline
\end{tabular}

Here ERTP $=$ Escherichia coli Resistant to Tetracycline and SRTP $=$ Salmonella Resistant to Tetracycline in the poultry isolates

Ciprofloxacin resistant Escherichia coli and Salmonella spp isolates from hospital samples can grow in higher concentration of ciprofloxacin $3000 \mu \mathrm{g} / \mathrm{ml}$. on the other hand tetracycline resistant Escherichia coli and Salmonella spp. isolates from poultry can grow in tetracycline concentration $150 \mu \mathrm{g} / \mathrm{ml}$. (Table 2 and Table 3) Multidrug resistance in Salmonella is not uncommon [22] reported multidrug resistant Salmonella from human and food animals in England and Wales. In this study, all the isolates are subjected to antibiotic susceptibility test against other commercial antibiotics like Penicillin G, Ampicillin, and Amoxicillin. The isolates of Escherichia coli and Salmonella spp. from hospital sample are multidrug resistant. (Table 4) 
Table 3. Analysis of resistant pattern of 8 Escherichia coli and 5 Salmonella isolates from poultry sample in different concentration of Ciprofloxacin

\begin{tabular}{|c|c|c|c|c|c|}
\hline Isolates & $\begin{array}{l}\text { Conc. of } \\
\text { ciprofloxacin }\end{array}$ & $\begin{array}{l}\text { Absorbance at } \\
590 \mathrm{~nm}\end{array}$ & Isolates & $\begin{array}{l}\text { Conc. of } \\
\text { ciprofloxacin }\end{array}$ & $\begin{array}{l}\text { Absorbance at } \\
590 \mathrm{~nm}\end{array}$ \\
\hline \multirow{3}{*}{ ERCH1 } & 1000 & 0.24 & \multirow{6}{*}{ SRCH1 } & 500 & 0.22 \\
\hline & 2000 & 0.19 & & 1000 & 0.17 \\
\hline & 3000 & 0.17 & & 2000 & 0.11 \\
\hline \multirow{3}{*}{ ERCH2 } & 1000 & 0.44 & & 3000 & 0.06 \\
\hline & 2000 & 0.38 & & 500 & 0.56 \\
\hline & 3000 & 0.24 & & 1000 & 0.54 \\
\hline \multirow{4}{*}{ ERCH3 } & 1000 & 0.22 & \multirow[t]{3}{*}{$\mathrm{SRCH} 2$} & 2000 & 0.35 \\
\hline & 2000 & 0.19 & & 3000 & 0.14 \\
\hline & 3000 & 0.1 & & 500 & 0.42 \\
\hline & 1000 & 0.2 & & 1000 & 0.24 \\
\hline \multirow[t]{3}{*}{ ERCH4 } & 2000 & 0.18 & \multirow[t]{2}{*}{ SRCH3 } & 2000 & 0.19 \\
\hline & 3000 & 0.1 & & 3000 & 0.17 \\
\hline & 1000 & 0.17 & & 500 & 0.48 \\
\hline \multirow[t]{3}{*}{ ERCH5 } & 2000 & 0.11 & \multirow{3}{*}{ SRCH4 } & 1000 & 0.42 \\
\hline & 3000 & 0.06 & & 2000 & 0.18 \\
\hline & 1000 & 0.26 & & 3000 & 0.1 \\
\hline \multirow[t]{3}{*}{ ERCH6 } & 2000 & 0.22 & \multirow{5}{*}{ SRCH5 } & 500 & 0.56 \\
\hline & 3000 & 0.15 & & 1000 & 0.48 \\
\hline & 1000 & 0.2 & & 2000 & 0.32 \\
\hline \multirow[t]{2}{*}{ ERCH7 } & 2000 & 0.12 & & 3000 & 0.09 \\
\hline & 3000 & 0.1 & & & \\
\hline \multirow{3}{*}{ ERCH8 } & 1000 & 0.25 & & & \\
\hline & 2000 & 0.22 & & & \\
\hline & 3000 & 0.01 & & & \\
\hline
\end{tabular}

Prevalence of Salmonella in Iran (33\%) is less than many developing countries, including $51 \%$ in Argentina, 68\% in Ethiopia, $72 \%$ in Thailand [23]. The Salmonella contamination percentages in poultry products are generally lower in the most developed countries [24].

Our findings indicate the prevalence of antibiotic-resistant Escherichia coli and Salmonella in hospital wastes is high. All Salmonella isolates were resistant to ciprofloxacin; these results are similar to those reported by others. Resistance to tetracycline, Penicillin and fluoroquinolone was the most intriguing finding of our present study. A recent study from Iran of clinical isolates of Campylobacter spp. revealed 62\% were resistant to ciprofloxacin [25]. Administration of fluoroquinolones as the first choice of treatment for acute diarrhea in Bangladesh may need to be reconsidered. Failure of fluoroquinolones in treatment of enteric infections in humans in Austria has been reported by [28].

Table 4. Antibiotic sensitivity test for ciprofloxacin and tetracycline resistant Escherichia coli spp. and Salmonella spp. from hospital isolates against several commercial antibiotic discs (Hi-media)

\begin{tabular}{lllllll}
\hline Strain & \multicolumn{7}{l}{ Antibiotic sensitivity Zone diameter $(\mathbf{m m})$} & \\
\hline Isolates from & Cipro. & Pen G. & Amp. & Amox. & Tetracyc. & Resistance \\
\hline ERCH1 & 0 & 0 & 0 & 0 & 0 & MDR in Hospital sample \\
ERCH2 & 0 & 0 & 0 & 0 & 0 & MDR in Hospital sample \\
ERCH3 & 0 & 0 & 0 & 0 & 0 & MDR in Hospital sample \\
ERCH4 & 0 & 0 & 0 & 0 & 0 & MDR in Hospital sample \\
ERCH5 & 0 & 0 & 0 & 0 & 0 & MDR in Hospital sample \\
ERCH6 & 0 & 0 & 0 & 0 & 0 & MDR in Hospital sample \\
ERCH7 & 0 & 0 & 0 & 0 & 0 & MDR in Hospital sample \\
ERCH8 & 0 & 0 & 0 & 0 & 0 & MDR in Hospital sample \\
SRCH1 & 0 & 0 & 0 & 0 & 0 & MDR in Hospital sample \\
SRCH2 & 0 & 0 & 0 & 0 & 0 & MDR in Hospital sample \\
SRCH3 & 0 & 0 & 0 & 0 & 0 & MDR in Hospital sample \\
SRCH4 & 0 & 0 & 0 & 0 & 0 & MDR in Hospital sample \\
SRCH5 & 0 & 0 & 0 & 0 & 0 & MDR in Hospital sample \\
\hline
\end{tabular}

$E R \overline{C H}=$ E.coli Resistant to Ciprofloxacin and SRCH= Salmonella Resistant to Ciprofloxacin from the hospital samples isolates, $0=$ No Zone of Inhibition was observed, MDR= Multi Drug Resistant. 
Tetracycline was the second most frequently used type of antibiotics in hospitals in Bangladesh. In Bangladesh, poultry is often treated with tetracycline and ciprofloxacin. Tetracycline is used for growth promotion of livestock. During our study we found 12 Escherichia coli and 5 Salmonella isolates from poultry samples were resistant to Tetracycline and Ciprofloxacin [26] reported that Escherichia coli isolates from poultry and poultry environment of Bangladesh are resistant to Ampicillin, Penicillin G, Ciprofloxacin, Tetracycline, Chloramphenicol, Neomycin, Kanamycin. Therefore all the isolates of poultry samples may be multidrug resistant.

We think that development of multidrug resistant microbial strain is not good sign for a country like Bangladesh. Bangladesh is a highly dense populated country; here peoples are not well educated and not conscious about health and microbial contamination, drainage and sewage systems are not well managed. During rainy season maximum area of the Chittagong city goes under water due to insufficient swage and drainage and has a great chance for spreading all over the city and may create serious health vulnerability. If multidrug resistance develops in such way, in future we may not get resistant antibiotic. For development of new antibiotic or other chemotherapeutic agents no fruitful research under way. So we have to think twice before prescribing and using of antibiotic. To reduce development of resistance in these pathogens, surveillance, monitoring of resistance, prudent use, educational programs, research and the use of alternatives to antimicrobial treatments like vaccination are recommended by the WHO [27]

\section{Conclusion}

The occurrences of ciprofloxacin and tetracycline resistance E.coli and Salmonella in the hospital wastes and poultry wastes is really an alarming factor for public health. This study revealed that different types of antibiotics are used in hospitals for treating diseases. After application, those antibiotics may be excreted by the patient or raw antibiotics can be found in the wastes as hospital discharges. These wastes are discharged in the environment from the hospitals. These can develop resistant microflora against those antibiotics in the environment. That is why all the isolated ciprofloxacin resistant E.coli and Salmonella showed resistance to common antibiotics used in $\mathrm{CMCH}$. The presence of multidrug resistant pathogen in hospital wastes may contribute to develop potential problem in public health. In poultry wastes also antibiotic resistant microflora is developing and it is alarming for us. This study in some extent favors the necessity of taking immediate step to solve this problem. In both hospital and poultry the use of antibiotics must be under recommendation by WHO [27] due to control antibiotic resistance.

\section{Acknowledgement}

We are thankful to Chittagong Medical College Hospital and Jayson Poultry farm for their kind help during collection of samples. We are grateful to Chittagong Ma-O- Sheshu Hospital authority for their kind permission to use the microbiology lab.

\section{CONSENT}

"All authors declare that "written informed consent was obtained from the patient (or other approved parties) for publication of this case report and accompanying images. A copy of the written consent is available for review by the Editorial office/Chief Editor/Editorial Board members of this journal."

\section{ETHICAL APPROVAL}

All authors hereby declare that "Principles of laboratory animal care" (NIH publication No. 85-23, revised 1985) were followed, as well as specific national laws where applicable. All experiments have been examined and approved by the appropriate ethics committee.

\section{COMPETING INTERESTS}

Authors have declared that no competing interest exists.

\section{References}

[1] Cretikos, M., Telfer, B., and McAnulty, J. (2008). Enteric disease outbreak reporting, New South Wales, Australia, 2000 to 2005. N SWPublic Health Bullettin, 19(1-2), 3-7.

[2] Castanon, J. I. (2007). History of the use of antibiotic as growth promoters in European poultry feeds. Poultry Science, 86, 24662471.

[3] Armstrong GL, Hollingsworth J, Morris JGJr. (1996). Emerging food borne pathogens: Escherichia coli 0157: H7 as a model of entry of a new pathogen into the food supply of the developed world. Epidemiological Review, 18, 29-51.

[4] Jawetz E, Melnick J, Adelberg EA. (1984). Review of Medical Microbiology. 16th ed. Los Altos, California: Long Medical Publication, pp. 122-144.

[5] Barnes HJ and Gross WB. (1997). Colibacillosis in Diseases of Poultry. 10th ed. B. W. Calnek, (Ed.), Mosby-Wolf Publication Ltd., London, UK, pp.131-139.

[6] Daini OA, Ogbulo OD, Ogunledun A. (2005). Quinolones Resistance and R-plasmids of some gram negative enteric Bacilli. Afr. J. Clin. and Exp. Micro., 6, 14-19. 
[7] Gross WB. (1994). Diseases due to Escherichia coli in poultry. pp. 237-260. In Gyles CL (ed.) Escherichia coli in domesticated animals and humans. CAB International. Wallingford, UK.

[8] Chakraborty P. (1995). A Text Book of Microbiology. 1st ed. New Central Book Agency (P) Ltd. pp.149-150.

[9] Crump JA, Lubsy SP and Mintz ED. (2004). The global burden of enteric fever. Bull. W. H. O., 82, 346-353.

[10] Bhal R and Bhatnagar S. (2005). Typhoid and paratyphoid fever. Lancet, 366, 749-762.

[11] Sayeed ASM, Mahmud N, Hakim MA. Reduced Susceptibility to Fluoroquinolone in Salmonella typhi and some Molecular Characteristics of Fluoroquinolone Resistance in Indigenous Isolates Published in Bangladesh J Microbial, Volume 27, Number 2, December 2010, pp 38-41.

[12] Threlfall EJ and Ward LR. (2001). Decreased susceptibility to ciprofloxacin in Salmonella enterica serotype Typhi, United Kingdom. Emerg Infect Dis., 7, 448-450.

[13] Wain J, Hoa NTT, Chinh NT, Vinh H, Everett MJ, Diep TS, Day NPJ, Solomon T, White NJ, Piddock LJ and Parry CM. (1997). Quinolone-resistant Salmonella typhi in VietNam: molecular basis of resistance and clinical response to treatment. Clin Infect Dis., 25, 1404-1410.

[14] Dimitrov T, Udo EE, Albaksami O, Kilani AA and Shehab EMR.(2007). Ciprofloxacin treatment failure in a case of typhoid fever caused by Salmonella enterica serotype Paratyphi A with reduced susceptibility to ciprofloxacin. J Med Microbiol., 56, 277-279.

[15] Dashti AA, Jadaon MM, Habeeb F, West PW, Panigrahi D and Amyes GBS. (2008). Salmonella enterica serotype Typhi in Kuwait and its reduced susceptibility to ciprofloxacin. J Chemother., 20, 38-43.

[16] Pelczar MJ. Cham E.C.S, Krieg N. R. Pelczar M.F. (1993), Microbiology, Tata McGraw Hill, New Delhi.

[17] Eklund, C. and Lankford, C.E. (1967). Laboratory Manual for General Microbiology. Prentice-Hall, Inc., Englewood Cliffs, NJ, pp 299.

[18] MacFaddin JF, ed(2000). Biochemical Tests for Identification of Medical Bacteria. 3rd ed. Philadelphia, Lippincott Williams and Wilkins, pp. 363-7.

[19] Claus, G.W. (1989). Understanding Microbes: A Laboratory Textbook for Microbiology. W.H. Freeman and Co. ${ }^{\circledR}$ New York.

[20] Beishir, L. (1991). Microbiology in Practice: A Self-Instructional Laboratory Course. Fifth ed. Harper Collins, New York.

[21] Barry AL. and Thornsberry C. (1985). Susceptibility Test, Diffussion test procedure. J. Chem. Pathol., 19, 492-500.

[22] Threlfall EJ, Ward LR and Rowe B. (1993). A comparison of multiple drug resistance in Salmonella from human and Food animals in England and Wales, 1981 and 1990. Epidemiol Infect., 111, 189-97

[23] Dallal Mohammad M. Soltan, Michael P. Doyle, Maryam Rezadehbashi, Hossein Dabiri, Maryam Sanaei , Shabnam Modarresi , Rounak Bakhtiari, Kazem Sharifiy, Mahnaz Taremi, Mohammad R. Zali, M.K. Sharifi-Yazdi, 2010. Prevalence and antimicrobial resistance profiles of Salmonella serotypes, Campylobacter and Yersinia spp. isolated from retail chicken and beef, Tehran, Iran. Food Control, 21, 388-392

[24] Cardinale, E., Perrier Gros-Claude, J. D., Tall, F., Cissé, M., Guèye, E. F., and Salvat, G. (2003). Prevalence of Salmonella and Campylobacter in retail chicken carcasses in Senegal. Revue D Elevage Et De Medecine Veterinaire Des Pays Tropicaux, 56, $13-16$.

[25] Feizabadi, M. M., Dolatabadi, S., and Zali, M. R. (2007). Isolation and drug-resistant patterns of Campylobacter strains cultured from diarrheic children in Tehran. Japanese Journal of Infectious Diseases, 60, 217-219.

[26] Muhammad Ali Akond, Saidul Alam, S. M. R. Hassan, Momena Sherin. (2009). Antibiotic Resistance of Escherichia coli Isolates from Poultry and Poultry Environment of Bangladesh. Internet Journal of Food Safety, 11, 19-23.

[27] WHO (2001). Antibiotic resistance: synthesis of recommendations by expert policy groups. WHO/CDS/DRS/2001.10.

[28] Feierl, G., Berghold, C., Furpass, T., and Marth, E. (1999). Further increase in ciprofloxacin resistant Campylobacter jejuni/coli in Styria, Austria. Clinical Microbiology and Infection, 5, 59-60. 